\title{
The HIV Blind Spot: Men and HIV Testing, Treatment and Care in Sub-Saharan Africa
}

\author{
Tim Shand, Hayley Thomson-de Boor, Wessel van den Berg, \\ Dean Peacock and Laura Pascoe
}

\begin{abstract}
Evidence shows that men are significantly underrepresented in HIV and AIDS testing and treatment services - both in sub-Saharan Africa and globally. HIV policies within sub-Saharan Africa also have insufficient focus on ensuring national HIV responses encourage men to test, access anti-retroviral treatment and support the disproportionate burden of HIV care on women. Addressing these challenges is important for everyone's sake and must be approached within a context of addressing power differentials between men and women at all levels. This includes challenging the broader patriarchal power structures in which gender plays out, such as the assumption that care work is 'women's work' and therefore less valued, and the rigidity of gender norms that encourage men to participate in risk-taking behaviours that put their life and the life of those around them in jeopardy.
\end{abstract}

\section{Introduction}

It is widely argued that one of the key drivers of HIV infection is gender inequality (UNAIDS 2012). The focus on how gender mediates HIV vulnerability has often centred, for important reasons, on how gender inequalities may impact on women's health and access to HIV services and create specific vulnerabilities for women to HIV infection (Ehrhardt et al. 2009). Arguably, as a result of this focus, policies, programmes and donor funding on addressing gender inequalities in the context of HIV have largely excluded a focus on men (Higgins et al. 2010). When men are included, the focus is frequently on men as the problem (e.g. as infectors of HIV) and with outcomes focusing specifically on improving women's health (Keeton 2007). There has been limited attention paid to how HIV affects men themselves, how to get men into testing or treatment, or understanding men's health-seeking behaviour within the context of the AIDS epidemic; it is, as Mills et al. (2009) states 'a major challenge, but one that is poorly recognized'.

There is, nevertheless, increased understanding that unhealthy constructions of masculinity - male gender norms associated with toughness and control, sexual prowess and heteronormativity, as a way of asserting manhood - can deter men from seeking HIV care and support, even at times of vulnerability and ill health (Reardon and Govender 2011; Bila and Ergot 2009; WHO 2007) or from being involved in their family's health and wellbeing. Male gender norms have also been associated with a range of risky sexual behaviours and practices, such as an unwillingness to use condoms, to get tested for HIV, or to reduce multiple and concurrent partnerships, all of which increase men's likelihood of contracting HIV and transmitting to others (Ehrhardt et al. 2009; Leclerc-Madlala 2008; Brown et al. 2005).

In understanding masculinities and HIV, it is critical to situate the HIV epidemic not just within gender-inequitable dynamics at an individual level, but also within the larger malecentric power structures that inequitably drive the epidemic (Shisana et al. 2010) and the allencompassing expectation of male authority that limits men's ability to show vulnerability. It is also important to foreground the power differentials 
between men and women (Chege 2005), which reinforce ideas of men's power over women despite also creating specific vulnerabilities for men. Such power differentials tend towards, for example, women bearing the main burden of HIV care $^{1}$ (Bila and Ergot 2009) and can reduce their ability to negotiate safer sex (Lindegger and Quayle 2010; Ehrhardt et al. 2009; LeclercMadlala 2008; Harrison et al. 2006). Another important manifestation of these power differentials is the widespread use and devastating impact of men's violence over women. Research shows consistently high levels of domestic and sexual violence against women (Barker $e t$ al. 2011), and that men who are violent towards their partners are more likely to engage in risky sexual behaviour, thus heightening their risk of contracting HIV, as well as infecting others (Jewkes and Morrell 2010; Jewkes et al. 2009; Kalichman et al. 2007; Dunkle et al. 2006).

So, what do we know about men and their propensity to seek HIV testing and treatment, or about how policies respond to this evidence? How do we develop interventions to encourage the uptake of prevention, testing, and treatment by men, in such a way that everyone benefits? We will discuss each of these questions in turn, below.

\section{Men, HIV testing, treatment and PMTCT}

There is a persistent blind spot around HIV prevention and treatment for men and their related burden of disease (Hawkes and Buse 2013; Cornell et al. 2011; Jeftha 2006). Research shows that, in addition to men having lower HIV testing rates in sub-Saharan Africa than women, the top ten contributors to the global disability-adjusted life-years (DALY) actually present greater burdens on men than women (Hawkes and Buse 2013). Within HIV, negative perceptions of HIV as a threat to notions of masculinity (Wyrod 2011) can prevent men from establishing and disclosing their status (Dageid et al. 2012), acknowledging their symptoms or engaging with HIV treatment (Jewkes and Morrell 2010).

There is also evidence that men are at a distinct disadvantage regarding the rollout of antiretroviral treatment (ART) in sub-Saharan Africa (Cornell et al. 2011). Disproportionately fewer men than women are accessing ART across Africa (Muula et al. 2007), and even those who do access treatment are less likely to continue ART than their female counterparts (Siu et al. 2012).
A recent WHO report stated that of the 44 per cent of HIV-positive men who were eligible for ART in the African region, only 36 per cent were receiving it by the end of 2011 (WHO 2013). In South Africa, about 55 per cent of those living with HIV are women but more than two-thirds of patients receiving public sector ART are female (Cornell et al. 2010). In Zambia, 54 per cent of those living with HIV are women yet 63 per cent of adults starting ART in Lusaka were female (Stringer et al. 2006).

Where men do access ART, they are more likely to interrupt treatment (Kranzer et al. 2010), and more likely to be lost to follow-up on ART (Ochieng Ooko et al. 2010). Men are often also found to present later, thus start ART with more advanced HIV disease (Cornell et al. 2009) and with additional complications (Stringer et al. 2006). Consequently, men are more likely than women to die on ART (Cornell et al. 2011; TaylorSmith et al. 2010; Mills et al. 2009). As Mills et al. (2011: 209 and 214) state, 'After adjustment for loss to follow-up, crude mortality rates (deaths per 1000 person-years) ranged from $26.9 \ldots$ in women to $43.9 \ldots$ in men... This finding builds on an emerging body of literature displaying consistent shortcomings in treatment programs involving men'. These gender discrepancies in ART uptake may reflect men's beliefs, informed by patriarchal ideas of what it means to 'be a man', that seeking health services is a sign of weakness or vulnerability, and that such services are not male-friendly (Nachega et al. 2006). Given that around 42 per cent of people living with HIV in sub-Saharan Africa are men (UNAIDS 2012), two conclusions become hard to dismiss: (1) we must take seriously the need to increase men's uptake of HIV services; and (2) we must do so through gender-transformative programmes and interventions that challenge the broader patriarchal power structures that perpetuate gender inequality.

In addition to the need to engage men around their own HIV status and care, it is instructive to also address the potential role men have to play in the prevention of mother-to-child transmission (PMTCT). Multiple studies show that health outcomes are better for women, children and men when men are involved in PMTCT (Aluisio 2011). An evaluation of the 'Men as Partners and PMTCT' programme in South Africa showed a 46 per cent increase in men testing with their 
partners and an 87.6 per cent increase in the number of men joining their partners for PMTCT visits (Van den Berg et al. 2013).

The gap in men's knowledge of PMTCT is immense. The 2009 South African National Communication Survey found that only 10 per cent of men knew that exclusive formula feeding prevents transmission and that only 1 per cent knew the same about exclusive breastfeeding. Despite the evidence of benefits, and the gap in knowledge, the number of times the words 'men', 'man', 'male', 'father', 'parent', 'fatherhood' or 'dad' appeared in the 2010 South African National PMTCT Guidelines was zero (DoH RSA 2010). One must approach strategies to involve men in PMTCT with caution, but structures to support such involvement, should the women choose it as appropriate, are clearly not in place.

The consequences of failing to address broader patriarchal power structures that support harmful male gender norms that limit men's ability to both benefit from and provide health care, as well as inadequate health services that take into account men and women's specific health needs have been significant. Men have much higher HIV-related mortality rates than women, as we have seen. While men may often have more economic or political privileges than women, in terms of HIV-related health services, men are not accessing the medical assistance they need. Both women and men stand to benefit from an increase in men's uptake of health services (Mills et al. 2009).

A lack of focus on men and HIV also has negative consequences for women. As previously noted, women typically carry the major share of care in homes and health facilities. Poverty makes caretaking and the other economic hardships that women suffer as a result of illness, medication, burial and funeral costs that much more apparent. These gender inequalities that play out at the individual level are also negatively impacted by patriarchal ideals, which dictate caring roles as feminine and therefore less valued, at the same time as encouraging men to participate in risktaking behaviours that put their life and the life of those around them in jeopardy.

\section{HIV policy context in Africa}

Activities to engage men in HIV work have been developing over the last decade, particularly in the area of HIV prevention and the prevention of sexual and gender-based violence, which has been linked to HIV vulnerability (Jewkes et al. 2009; Vetten and Bhana 2001). Nevertheless, progress has been slower in areas beyond HIV prevention, or beyond activities focused on reaching individual men for changing their attitudes and behaviours. It is increasingly becoming recognised that public policies and engagement with the public sector are central to the goal of scaling up work with engaging men, and achieving societal changes in gender norms (Shand et al. 2012; Cornwall et al. 2011). Such policies can affect behaviour change and access to services beyond the individual level. As described above, policy formation and implementation are influenced by the patriarchal legacies of society that often leave such decisions predominantly in the hands of men. As such, shifting policy discourses will arguably further engage men in positions of power in gender equality policymaking. It is essential, therefore, to build a shared policy agenda on gender equality and engaging men and boys between civil society, national policymakers and regional bodies, as well as to ensure that such issues are prioritised within existing laws and policies. Currently, however, few HIV policies in Africa prioritise the need to increase men's uptake of and involvement in testing and treatment services, as highlighted by an analysis conducted by Sonke Gender Justice (unpublished).

Sonke's analysis aimed to assess the extent to which HIV policies, primarily National Strategic Plans (NSPs), acknowledge the importance of promoting gender transformation and engaging men and boys to reduce both women's and men's gender-related vulnerabilities. The policies were assessed according to the extent to which they:

- acknowledged the importance of gender within HIV work;

- committed to challenge or transform gender norms and encourage men to use condoms, increase their uptake of voluntary counselling and testing (VCT) and treatment, their involvement in the care economy, PMTCT processes and the prevention of gender-based violence (GBV);

- adequately prioritised male circumcision rollout, including with gender equality training; and

- addressed the needs of vulnerable men and boys. 
$\mathrm{NSPs}^{2}$ from 13 African countries were analysed., This analysis, conducted on behalf of the MenEngage Africa Network, ${ }^{5}$ revealed that few NSPs highlight the need to increase men's uptake of testing and treatment services. The need to involve men in PMTGT processes, on the other hand, is often highlighted within NSPs.

Most NSPs do acknowledge the importance of gender within HIV work, but very few expand this to include work with men. This limited conception of gender as women is evident in almost all the NSPs that were reviewed, and can also be noted in the use of women-focused terms such as 'maternal' in policies relating to sexual and reproductive health (Klugman et al. 2000). This conflation between the terms 'gender' and 'women', reinforces a lack of understanding about the specific gendered vulnerabilities or needs men may have within the context of the epidemic. Critically, it does not serve women well as NSPs or other related policies do not prioritise engaging men as potential partners in women's health and wellbeing.

Policies from five out of the 13 countries analysed were rated as 'inadequate' in terms of identifying the need to address and transform gender norms and patriarchal power structures, in order to reduce the spread and effects of HIV. Six countries' policies were rated as 'needing improvement' in this area, while two were rated as 'adequate', namely Tanzania and South Africa. The Tanzanian Second National Multisectoral Strategic Framework on HIV and AIDS, 2008-2012 (TACAIDS 2007)(NSF) notes a range of unhealthy gender norms that need to be challenged, including 'cultural forms which promote female subordination and irresponsible male behaviour' (p39); 'male assertiveness and aggression' (p53); while the National Multisectoral HIV Prevention Strategy, 2009-2012 (United Republic of Tanzania 2009) also identifies 'male infidelity' (pp12-13). The Tanzanian NSF also suggests that 'influential men [should]... promote gender equity and social transformation' (p57), through engaging community and cultural leaders to facilitate behaviour change and HIV prevention activities. Unfortunately, few NSPs outline such specific priorities in terms of addressing and transforming gender norms in relation to HIV.

In terms of identifying the need to increase men's uptake of testing services, policies from eight out of the 13 countries analysed were rated as 'inadequate'. Three were rated as 'needing improvement' and two were rated as 'adequate', namely South Africa and Zambia. Importantly, the South African NSP links the need to increase men's uptake of testing services with current data that reveal men's currently low rates of access. The NSP goes on to say that 'efforts must be made to increase men's health-seeking behaviour, including participation in HCT [HIV counselling and testing]' (p40). The Zambian NSP notes that more than 80 per cent of Zambians do not know their HIV status, and commits to scaling up access to HCT services 'with attention to couples counselling, male involvement and integration with other services' (p39). Unfortunately, no other NSPs analysed identified this need to address increased access to testing for men.

Policies from seven out of the 13 countries were rated as 'inadequate' in terms of identifying the need to increase men's uptake of treatment services, while five were rated as 'needing improvement', and one (South Africa) was rated as adequately acknowledging this need. While the Tanzanian NSF (rated as needing improvement) notes that 'more women than men are currently on treatment, mainly because health facilities are visited more by women than by men, due to the focus on reproductive and child health services', and seeks to remedy this by promoting 'genderresponsive research and its application on the clinical management of AIDS clients' (p72), there is no firm commitment to encourage men to seek treatment or to ensure that health facilities will be made more accommodating for men and boys.

Regarding men and PMTCT, policies from seven out of the 13 countries analysed were rated as 'adequate' in terms of identifying the need for male involvement in PMTCT processes, four as 'needing improvement' and only two as 'inadequate'. It is far more common to find men's involvement in PMTCT processes highlighted within NSPs, as compared with any other service. While this is definitely encouraging, as PMTCT processes can be used as a gateway for men to enter into broader HIV and sexual and reproductive health (SRH) services, these reasons are not always outlined by NSPs. National plans often fail to outline potential strategies around how to encourage men to become involved in PMTCT and typically do not acknowledge that 
encouraging men to become involved in such processes may prove challenging. NSPs seldom acknowledge broader forces impacting on and influencing men's behaviour in this regard, such as gender norms regarding health-seeking behaviour, or even the ability of many men to be involved in a process with their partners, without taking the lead or taking charge.

In other policy areas, such as medical male circumcision (MMC), which specifically discuss targeting men, there is less focus on using such policies as an opportunity to engage men around gender norms or even for other HIV prevention services. In addition, men are hardly ever mentioned in terms of addressing their attitudes towards condom use, or increasing their involvement in home-based care. Increasing men's involvement in home-based care would not only reduce the burden of this care on women, but begin to challenge the patriarchy-informed assumption that such care is feminised and therefore less valued.

It is therefore clear that much work remains to be done on a policy level in terms of prioritising the need to engage men in testing and treatment services, and to frame their engagement in PMTCT processes in a way that will maximise the potential for effective implementation on the ground. Changes that will impact on the spread and effects of HIV will not be possible unless policies acknowledge the effects of gender norms, and the need to transform such norms, in order to influence behaviour and improve access to services.

\section{Moving forward}

In order to address the challenges outlined above, we propose six key directions for more effectively and constructively engaging men in more gender-equitable strategies to address HIV.

First, there is a need to shift the global 'gender and HIV' discourse, which to a large extent remains focused only on women. The recent UNAIDS update report (UNAIDS 2013), as well as reports from PEPFAR and the Global Fund, for example, make little mention of engaging men. The required shift would not only engage men more broadly in HIV prevention, treatment, care and support for others, but also in addressing their own specific HIV needs, as well as challenging patriarchy-informed assumptions that health, particularly SRH, is solely the responsibility of women. As part of this, NGOs should both challenge and collaborate with UNAIDS, PEPFAR and the Global Fund to assist them in strengthening their analyses and focus on men and HIV services. Additionally, health service data collected need to be sexdisaggregated in order to build a strong evidence base upon which to shift this discourse.

Second, a focus on gender equality and services for men and boys should be integrated into national policies, as well as into various UN and bilateral agreements. A key first step would be for civil society and governments to strengthen the language within their NSPs on HIV to address their aforementioned policy gaps and in order to increase men's use of HIV services, as well as to strengthen their support for women's use of services.

Third, health systems need to be made more 'male-friendly', in particular to address men's specific HIV needs around testing and treatment. This can include taking HIV services to men and women in communities, given the clear evidence that men use HIV services more when those services are community-based.

Health service providers should also be educated and skilled up to address men's specific HIV needs. Technical assistance on how to involve men and boys in HIV services should be provided more broadly: for example by existing organisations working with men for gender equality, who have proven a level of capacity and leadership. Research into men's current attitudes towards accessing testing, treatment, MMC and PMTCT services should also be explored in order to better shape interventions.

Fourth, new technologies like PrEP, microbicides, and treatment as prevention can only be effective if men understand their vested interest in the rollout of such technologies and more men access HIV services. Men need to be educated around the importance of knowing their status, as well as the value and use of such technologies in HIV prevention and reduction in transmission. Thought should also be given to ways that the design, testing and potential rollout of such technologies can engage men, particularly male partners, where appropriate. Constructively engaging men at these various stages will not only benefit men and women, but will challenge overarching power 
structures that assume female responsibility for HIV prevention and leave it to them.

Fifth, programming and policies on engaging men in HIV that are evidence-based and have been shown to be effective must be scaled up. Opportunities, such as MMC rollout, should be pursued with greater rigour. Mass media campaigns that encourage men and boys to get tested should be considered. The disproportionate burden of HIV care on women must be addressed by finding ways to engage men more in the HIV care economy.

\section{Notes}

1 'Burden of care' refers both to the burden of safe sex and of family planning, knowing one's HIV status and seeking treatment, but also to the responsibility for providing care for sick family members, which has been increased by the HIV epidemic (Akintola 2008).

2 In some cases other HIV-related policies were also analysed, such as condom or PMTCT policies.

3 Ethiopia, 2009-2011; Kenya, 2010-2013; Malawi, 2010-2012; Mozambique, 2010-2014;

\section{References}

Akintola, O. (2008) Towards Equal Sharing Of Aids Caring Responsibilities: Learning From Africa, Geneva: United Nations

Aluisio, A.; Richardson, B.A.; Bosire, R.; JohnStewart, G.; Mbori-Ngacha, D. and Farquhar, C. (2011) 'Male Antenatal Attendance and HIV Testing are Associated with Decreased Infant HIV Infection and Increased HIV-free Survival', Journal of Acquired Immune Deficiency Syndromes 56.1: 76-82

Barker, G.; Contreras, J.M.; Heilman, B.; Singh, A.K.; Verma, R.K. and Nascimento, M. (2011) Evolving Men: Initial Results from the International Men and Gender Equality Survey (IMAGES), Washington DC: International Center for Research on Women (ICRW) and Rio de Janeiro: Instituto Promundo

Bila, B. and Ergot, M. (2009) 'Gender

Asymmetry in Healthcare-facility Attendance of People Living with HIV/AIDS in Burkina Faso', Social Science and Medicine 69.6: 854-61

Brown, J.; Sorrell, J. and Raffaelli, M. (2005) 'An Exploratory Study of Constructions of Masculinity, Sexuality and HIV/AIDS in Namibia, Southern Africa', Gulture, Health and Sexuality 7.6: 585-98
Lastly, it is crucial to ensure that approaches are gender-transformative, carried out in solidarity and concert with struggles for women's empowerment, and go beyond targeting individual behaviour to also challenge patriarchal structures through which gender inequality plays out on a day-to-day basis. Such approaches should acknowledge the negative impacts that certain male gender norms have on both men and women, and seek to challenge such norms - at individual, community and institutional levels - to develop more genderequitable communities and nations.

Namibia, 2011-2016; Rwanda, 2009-2012; Sierra Leone, 2011-2015; South Africa, 2012-2016; Swaziland, 2009-2014; Tanzania, 2008-2012; Uganda, 2008-2012; Zambia, 2011-2015; Zimbabwe, 2011-2014.

4 As this research began at the end of 2011, four of the 13 NSPs that were analysed are now out of date, having ended in 2012 and in the case of Ethiopia, 2011.

5 See www.menengage.org.

Chege, J. (2005) 'Interventions Linking Gender Relations and Violence with Reproductive Health and HIV: Rationale, Effectiveness and Gaps', Gender, Culture and Rights, Agenda Special Focus 115: 114-23

Cornell, M.; McIntyre, J. and Myer, L. (2011) 'Men and Antiretroviral Therapy in Africa: Our Blind Spot', Tropical Medicine and International Health 16.7: 828-9

Cornell, M.; Grimsrud, A.; Fairall, L.; Fox, M.P.; van Cutsem, G.; Giddy, J.; Wood, R.; Prozesk, H.; Mohapi, L.; Graber, C.; Egger, M.; Boulle, A. and Myer, L. (2010) 'Temporal Changes in Programme Outcomes among Adult Patients Initiating Antiretroviral Therapy across South Africa 2002-2007', AIDS 24: 2263-70

Cornell, M.; Myer, L.; Kaplan, R.; Bekker, L. and Wood, R. (2009) 'The Impact of Gender and Income on Survival and Retention in a South African Antiretroviral Therapy Programme', Tropical Medicine and International Health 14.7: $1-10$

Cornwall, A.; Edström, J. and Greig, A. (eds) (2011) Men and Development: Politicizing Masculinities, London and New York: Zed Books

Dageid, W.; Govender, K. and Gordon, S.F. (2012) 'Masculinity and HIV Disclosure 
among Heterosexual South African Men: Implications for HIV/AIDS Intervention', Culture, Health and Sexuality 14.8: 925-40

DoH RSA (Department of Health, Republic of South Africa) (2010) South African National PMTCT Guidelines, www.fidssa.co.za/images/ PMTCT_Guidelines.pdf (accessed 2 October 2011)

Dunkle, K.L.; Jewkes, R.K.; Nduna, M.; Levin, J.; Jama, N.; Khuzwayo, N. and Duvvury, N. (2006) 'Perpetration of Partner Violence and HIV Risk Behaviour among Young Men in the Rural Eastern Cape, South Africa', AIDS 20.16: 2107-14

Ehrhardt, A.A.; Sawires, S.; McGovern, T.; Peacock, D. and Weston, M. (2009) 'Gender, Empowerment, and Health: What is it? How Does it Work?', Journal of Acquired Immune Deficiency Syndromes 51.3: 96

Harrison, A.; O’Sullivan, L.F.; Hoffman, S.; Dolezal, C. and Morrell, R. (2006) 'Gender Role and Relationship Norms among Young Adults in South Africa: Measuring the Context of Masculinity and HIV Risk', Journal of Urban Health 83.4: 709-22

Hawkes, S. and Buse, K. (2013) 'Gender and Global Health: Evidence, Policy, and Inconvenient Truths', The Lancet 381: 1783-7

Higgins, J.A.; Hoffman, S. and Dworkin, S.L. (2010) 'Rethinking Gender, Heterosexual Men, and Women's Vulnerability to HIV/AIDS', American Journal of Public Health 100.3: 435

Jeftha, A. (2006) 'The Construction of Masculinity and Risk-taking Behaviour among Adolescent Boys in Seven Schools in the Western Cape', doctoral dissertation, University of the Western Cape

Jewkes, R. and Morrell, R. (2010) 'Gender and Sexuality: Emerging Perspectives from the Heterosexual Epidemic in South Africa and Implications for HIV Risk and Prevention', Journal of the International AIDS Society 13.1: 6

Jewkes, R.; Sikweyiya, Y.; Morrell, R. and Dunkle, K. (2009) 'Understanding Men’s Health and Use of Violence: Interface of Rape and HIV in South Africa', Cell 82.442: 3655

Kalichman, S.C.; Simbayi, L.C.; Cain, D.; Cherry, C.; Henda, N. and Cloete, A. (2007) 'Sexual Assault, Sexual Risks and Gender Attitudes in a Community Sample of South African Men', AIDS Care 19.1: 20-7

Keeton, C. (2007) 'Changing Men's Behaviour can Improve Women s Health', Bulletin of the World Health Organization 85.7: 505-6
Klugman, B.; Stevens, M. and van den Heever, A. (2000) 'South Africa', in Shepard Forman and Remita Ghosh (eds), Promoting Reproductive Health: Investing in Health for Development, Boulder CO: Lynne Rienner Publishers Kranzer, K.; Lewis, J.J.; Ford, N.; Zeinecker, J.; Orrel, G.; Lawn, S.D.; Bekker, L.G. and Wood, R. (2010) 'Treatment Interruption in a Primary Care Antiretroviral Therapy Program in South Africa: Cohort Analysis of Trends and Risk Factors', Journal of AIDS 55.3: e 17-23

Leclerc-Madlala, S. (2008) 'Age-disparate and Intergenerational Sex in Southern Africa: The Dynamics of Hypervulnerability', AIDS 22: S17-25

Lindegger, G. and Quayle, M. (2010)

'Masculinity and HIV/AIDS', in P. Rohleder, L. Swartz, S. Kalichman and L. Simbayi (eds), HIV/AIDS in South Africa 25 Years On, London: Springer

Mills, E.; Ford, N. and Mugyenyi, P. (2009) 'Expanding HIV Care in Africa: Making Men Matter', The Lancet 374: 275-6

Mills, E.; Bakanda, C.; Birungi, J.; Chan, K.; Ford, N.; Cooper, C.L.; Nachega, J.B.; Dybul, M. and Hogg, R.S. (2011) 'Life Expectancy of Persons Receiving Combination Antiretroviral Therapy in Low-Income Countries: A Cohort Analysis from Uganda', Annals of Internal Medicine 155.4: 209-18

Muula, A.S.; Ngulube, T.J.; Siziya, S.; Makupe, C.M.; Umar, E.; Prozesky, H.W.; Wiysonge, C.S. and Mataya, R.H. (2007) 'Gender Distribution of Adult Patients on Highly Active Antiretroviral Therapy (HAART) in Southern Africa: A Systematic Review', BMC Public Health 7: 63

Nachega, J.; Hislop, M.; Dowdy, D.; Lo, M.; Omer, S.; Regensberg, L.; Chaisson, R. and Maartens, G. (2006) 'Adherence to Highly Active Antiretroviral Therapy Assessed by Pharmacy Claims Predicts Survival in HIVInfected South African Adults', Journal of Acquired Immune Deficiency Syndromes 43.1: 78-84

Ochieng-Ooko, V.; Ochieng, D.; Sidle, J.E.;

Holdsworth, M.; Wools-Kaloustian, K.; Siika, A.M.; Yiannoutsos, C.T.; Owiti, M.; Kimaiyo, S. and Braitstein, P. (2010) 'Influence of Gender on Loss to Follow-up in a Large HIV Treatment Programme in Western Kenya', Bulletin of the World Health Organization 88: 681-8

Reardon, C.A. and Govender, K. (2011)

"'Shaping Up": The Relationship between 
Traditional Masculinity, Conflict Resolution and Body Image among Adolescent Boys in South Africa', Vulnerable Children and Youth Studies 6.1: 78-87

Shand, T.; Phillips, L. and Pascoe, L. (2012) 'State of the Field in Activism, Programs and Policy for Engaging Men and Boys to Promote Gender Transformation', in Gilles Tremblay and François-Olivier Bernard (eds), Future Perspectives for Intervention, Policy and Research on Men and Masculinities: An International Forum, Harriman TN: Men's Studies Press

Shisana, O.; Rice, K.; Zungu, N. and Zuma, K. (2010) 'Gender and Poverty in South Africa in the Era of HIV/AIDS: A Quantitative Study', Journal of Women's Health 19.1: 39-46

Siu, G.E.; Wight, D. and Seeley, J. (2012) 'How a Masculine Work Ethic and Economic Circumstances affect Uptake of HIV Treatment: Experiences of Men from an Artisanal Gold Mining Community in Rural Eastern Uganda', Journal of International AIDS Society 14.1: 1-9

Sonke Gender Justice (unpublished) 'Analysis of NSPs from 13 African countries, 2011-2013'

Stringer, J.S.; Zulu, I.; Levy, J.; Stringer, E.M.; Mwango, A.; Chi, B.H.; Mtonga, V.; Reid, S.; Cantrell, R.A.; Bulterys, M.; Saag, M.S.; Marlink, R.G.; Mwinga, A.; Ellerbrock, T.V. and Sinkala, M. (2006) 'Rapid Scale-up of Anti-retroviral Therapy at Primary Care Sites in Zambia: Feasibility and Early Outcomes', Journal of the American Medical Association 296: 782-93

TACAIDS (2007) Second National MultiSectoral Strategic Framework on HIV and AIDS, 2008-2012, Dar es Salaam: Tanzania Commission for AIDS

Taylor-Smith, K.; Tweya, H.; Harries, A.D.; Schoutene, E. and Jahn, A. (2010) 'Gender Differences in Retention and Survival on Antiretroviral Therapy of HIV-infected Adults in Malawi', Malawi Medical Journal 22: 49-56 UNAIDS (2013) Update. UNAIDS Special Report, www.unaids.org/en/resources/presscentre/ pressreleaseandstatementarchive/2013/may/
20130521 prupdateafrica/\#d.en.79754 (accessed 5 August 2013)

UNAIDS (2012) Global Report: UNAIDS Report on the Global AIDS Epidemic 2012, www.unaids.org/ en/media/unaids/contentassets/documents/ epidemiology/2012/gr2012/20121120_UNAIDS _Global_Report_2012_with_annexes_en.pdf (accessed 5 August 2013)

United Republic of Tanzania (2009) National Multisectoral HIV Prevention Strategy, 2009-2012, Dar es Salaam: Prime Minister's Office, United Republic of Tanzania, www.aidstarone.com/sites/default/files/prevention/ resources/national_strategic_plans/Tanzania 2009-2012_Prevention_Strategy.pdf (accessed 11 November 2013)

Van den Berg, W.; Shand, T. and Peacock, D. (2013) 'Engaging Men and Boys in HIV Prevention and Treatment: A Systemic Approach', in R. Smith (ed.), Global HIV/AIDS Politics, Policy and Activism: Persistent Challenges and Emerging Issues, Westport CT: Praeger Publishers

Vetten, L. and Bhana, K. (2001) Violence, Vengeance and Gender: A Preliminary Investigation into the Links between Violence against Women and HIV/AIDS in South Africa, research report written for the Centre for the Study of Violence and Reconciliation, www.csvr.org.za/index.php/ publications/1605-violence-vengeance-andgender-a-preliminary-investigation-into-thelinks-between-violence-against-women-andhivaids-in-south-africa.html (accessed 25 October 2013)

WHO (2013) Global Update on HIV Treatment 2013: Results Impacts and Opportunities, Geneva: World Health Organization

WHO (2007) Engaging Men and Boys in Changing Gender-based Inequity in Health: Evidence from Programme Interventions, Geneva: World Health Organization

Wyrod, R. (2011) 'Masculinity and the Persistence of AIDS Stigma', Culture, Health and Sexuality 13.4: 443-56 